This item was submitted to Loughborough's Research Repository by the author.

Items in Figshare are protected by copyright, with all rights reserved, unless otherwise indicated.

\title{
Dynamics of group knowledge production in facilitated modelling workshops: an exploratory study
}

\author{
PLEASE CITE THE PUBLISHED VERSION
}

http://dx.doi.org/10.1007/s10726-014-9398-2

\section{PUBLISHER}

(C) Springer Science+Business Media Dordrecht (Published in cooperation with the Institute for Operations Research and the Management Sciences and its Section on Group Decision and Negotiation)

\section{VERSION}

AM (Accepted Manuscript)

\section{PUBLISHER STATEMENT}

This work is made available according to the conditions of the Creative Commons Attribution-NonCommercialNoDerivatives 4.0 International (CC BY-NC-ND 4.0) licence. Full details of this licence are available at: https://creativecommons.org/licenses/by-nc-nd/4.0/

\section{LICENCE}

CC BY-NC-ND 4.0

\section{REPOSITORY RECORD}

Tavella, Elena, and L. Alberto Franco. 2019. "Dynamics of Group Knowledge Production in Facilitated Modelling Workshops: An Exploratory Study”. figshare. https://hdl.handle.net/2134/16741. 


\title{
Dynamics of group knowledge production in facilitated modelling workshops: An exploratory study
}

\author{
Elena Tavella ${ }^{\mathrm{a}}$, L.A. Franco ${ }^{\mathrm{b}}$ \\ ${ }^{a}$ Department of Food and Resources Economics, University of Copenhagen,1958 Frederiksberg \\ C, Denmark \\ ${ }^{b}$ School of Business and Economics, Loughborough University, Leicestershire,LE11 3TU, UK
}

\begin{abstract}
The term 'facilitated modelling' is used in the literature to characterise an approach to structuring problems, developing options and evaluating decisions by groups working in a modelsupported workshop environment, and assisted by a facilitator. The approach involves an interactive process by which models are jointly developed with group members interacting face-to-face, with or without computer support. The models produced are used to inform negotiations about the nature of the issues faced by the group, , and how to address them. While the facilitated modelling literature is impressive, published empirical research rarely examines what actually happens in a facilitated modelling environment. The present study addresses this gap by reporting on exploratory empirical research undertaken to closely examine the conduct of facilitated modelling within its actual context of immediate use, namely, the workshop. Drawing on the knowledge-perspective of group communication, we conducted a micro-level analysis of a transcript of a facilitated modelling workshop held with the management team of an Alternative Food Network in the UK. Our analysis suggests that facilitated modelling interactions can take the form of three distinct group knowledge production patterns: generative, collaborative and assertive. Further, each pattern is characterised by a particular mix of communicative behaviours and model-supported interactions that has implications for the creation of new knowledge within the workshop. Our findings contribute to increase our understanding of the nature of facilitated modelling within its context of use.
\end{abstract}

Keywords: Facilitated modelling, workshops, knowledge production, group negotiation, microlevel analysis.

\section{Introduction}

Some group decision support scholars use the term 'facilitated modelling' to characterise approaches that combine group facilitation with participative modelling (e.g. Franco \& Montibeller, 2010; Franco \& Rouwette, 2011; Rouwette, 2011). The facilitated modelling approach involves an interactive process by which models are jointly developed with a group, face-to-face, in a workshop environment, and with or without the assistance of computer support (Ackermann \& Eden, 1994; Franco \& Montibeller, 2011). The models produced are used to inform negotiations about the nature of the issues of common concern, and how to address them. A number of facilitated modelling approaches have been developed in the operational research and systems fields over the last four decades. Also known as 'model-driven' group support systems, to distinguish them from their 'technology-driven' counterparts (Morton, Ackermann, \& Belton, 2003), they include well established methodologies such as strategic options development and analysis (Ackermann \& Eden, 2010; Eden \& Ackermann, 2001), journey making (Ackermann \& Eden, 2001; Ackermann \& Eden, 
2011a), strategic choice (Friend, 2001; Friend \& Hickling, 2005), decision conferencing (Phillips, 2007; Phillips \& Bana e Costa, 2007), and group model building (Rouwette \& Vennix, 2009; Vennix, 1995).

Applications of facilitated modelling approaches are extensively reported in the literature (Ackermann \& Eden, 2005; Bana e Costa, Lourenço, Oliveira, \& Bana e Costa, 2013; Cushman \& Rosenhead, 2004; Darling, Mumpower, Rohrbaugh, \& Vari, 1999; Eden \& Ackermann, 2013; Franco, 2008; Rouwette, Bastings, \& Blokker, 2011a; White, 2009). Typically, these studies offer thick descriptions of the application of a particular facilitated modelling approach, combined with rich, in-depth reflections about its perceived impact from the perspective of the 'facilitator' (e.g. Ackermann \& Eden, 2005; Eden \& Ackermann, 2013; Rouwette et al., 2011a), the 'facilitated' (e.g. Ackermann, 1996; Franco, 2008; Rouwette, Korzilius, Vennix, \& Jacobs, 2011b), or both. Yet with few notable exceptions (e.g. Ackermann \& Eden, 2011b; Shaw, Ackermann, \& Eden, 2003), we know very little about what actually happens within a facilitated modelling environment. The present exploratory study addresses this gap by reporting the findings of empirical research undertaken to examine how facilitated modelling is actually performed within its context of immediate use, namely, the workshop. Addressing this gap is important because it can help us unpack the 'black box' of facilitated modelling workshops, and enable us to identify the mechanisms through which facilitated modelling interactions evolve, moment-by-moment, among those involved, and how they contribute to the workshop products.

To conduct our research, we drew on the knowledge-perspective of communication (Mengis and Eppler 2008), which provides a useful means to better understand the type of group knowledge production processes that are central to facilitated modelling workshops (e.g. Eden, 1992; Franco, 2013). The knowledge-perspective of communication is concerned with understanding the factors that influence the ability of social actors to create or integrate new knowledge during conversational exchanges. We carried out a micro-level analysis of a transcribed audio recording of a facilitated modelling workshop held with the management team of an Alternative Food Network in the UK. The particular facilitated modelling approach used in this workshop was the Viable System Model (VSM) developed by Beer (1981, 1984, 1985a, b). Our analysis enabled us to identify three distinct group knowledge production patterns: generative, collaborative and assertive. Each of these patterns comprises a particular mix of communicative behaviours and model-supported interactions that influenced the extent to which new knowledge was created within the workshop.

In what follows we examine the links between facilitated modelling and knowledge creation, and describe the theoretical framework that informs our subsequent empirical work. Next, we explain our research methodology and present our findings. We conclude the paper with a discussion of how the findings of our exploratory study contribute to theoretical elaborations of facilitated modelling practice, and towards building the foundations for the effective conduct of facilitated modelling workshops.

\section{Theoretical framework}

The link between facilitated modelling approach and group knowledge production has been discussed by some scholars such as Eden (1992), Keys (2007a, b) and, more 
recently, Franco (2013). Indeed, whilst facilitated modelling can serve many instrumental purposes, group knowledge creation is arguably one of its more significant products (Franco, 2013). This is particularly the case when a group faces a problem situation that demands novel ways to tackle it. In this context, a group of individuals with the power to act and domain-specific understandings of, and interests in, the problem situation typically participates in a facilitated modelling workshop in order to develop new knowledge about, and novel responses to, that situation. New knowledge arises when the meanings attributed to the problem situation change, as modelling helps to transform the context and relationships between the different elements of that situation (Ackermann \& Eden, 2010; Eden, 1992). Thus new knowledge creation goes beyond creativity by implying the need for a new configuration of knowledge.

The capacity of facilitated modelling to enable the creation of new knowledge is, however, not always guaranteed. As Ackermann and Eden (2011a) note, when the models produced, and the analyses they enable, are used by the group either symbolically to deflect attention away from discussing the real issues, or as a vehicle for imposing particular perspectives, new knowledge and action is unlikely to be achieved. Therefore, the factors that may affect the potential capacity of facilitated modelling to enable new knowledge creation warrant a closer empirical examination. Specifically, there is a case for conducting an assessment of actual facilitated modelling practice in relation to group knowledge creation.

Comprehensive treatments of knowledge production are typically found outside the facilitated modelling literature. Therefore, we will draw on the knowledge-perspective of communication (Mengis \& Eppler, 2008), and mainly concentrate on the work by Tsoukas (2009). His conceptualisation of knowledge creation is grounded in the notion of dialogue-type interactions, which are arguably a key characteristic of the facilitated modelling approach to group decision support (Cronin, Midgley, \& Jackson, 2014; Franco, 2006).

Broadly, a dialogue-type interaction, whether it is model-supported or not, embodies a conversational form in which a turn-taking sequence of verbal exchanges takes place between at least two parties aiming to accomplish a collective goal (Barrett, 1999; Bohm, 1996; Isaacs, 1999; Luckmann, 1990; Walton, 1998, 2000, 2006; Yankelovich, 1999). Tsoukas (2009) argues that dialogue-type interaction implies "the possibility of mutual influence, and insofar as this is the case, we can talk of productive dialogue" (p.3, emphasis in the original). In productive dialogue each party potentially makes the other become aware of their individual limited perspectives, and motivates a search for broader perspectives, thus, each one potentially drawing insights he or she did not know they had (Merleau-Ponty, 1962; Tsoukas, 2009). When dialogue is unproductive, by contrast, individual contributions are fragmented and participants engaged in parallel conversations are unable to deal with the issues at hand (Bechky, 2003; Kogler, 1996; Tsoukas, 2009).

Tsoukas (2009) argues that dialogue is most likely to be productive when participants adopt a modality of interaction known as relational engagement. Participants are relationally engaged when they openly comment on each other's contributions and acknowledge their willingness to jointly resolve the issues at hand and maintain their 
social relationships (Andersen \& Chen, 2002; Cross, Morris, \& Gore, 2002; Möllering, 2006). Conversely, when the modality of calculated engagement is present, participants limit themselves to behaviours aimed at protecting positions or maximising individual gain. In this case the suspension required for participants to let themselves open to influence is not achieved, and dialogue is likely to be unproductive (Gratton \& Ghoshal, 2002; Tsoukas, 2009).

When participants are relationally engaged, they take distance from their customary and unreflective ways of acting. Through this process of 'self-distanciation' (Kogler, 1996; Tsoukas, 2009) participants gain critical insight into their organisational practices and routines, which increases their capacity to engage in a dialogue that is productive, and make the conceptual distinctions needed to deal with the problem at hand. When new distinctions are made, taken further in the dialogue and inter-subjectively accepted, new knowledge is created (Benner, 1994; Nonaka \& Takeuchi, 1995; Nonaka, Toyama, \& Byosiere, 2001; Tsoukas, 2003, 2009). Tsoukas (2009) argues that new knowledge is useful for tackling complex organisational problems and, when embodied in new organisational actions, processes, or practices, learning and innovation typically occurs (Edmondson, 2002; Hargadon, 2003; Hargadon \& Sutton, 1997; Tschang, 2007).

The conceptual distinctions that may lead to new knowledge creation are generated through three processes of (re)conceptualisation (Tsoukas, 2009): conceptual combination, conceptual expansion, and/or conceptual reframing. Conceptual combination involves combining two or more existing concepts to create a new concept that may have emergent attributes that are distinct from those of either of the constituent parts (Hampton, 1997; Sawyer, 2007). Conceptual expansion entails extending the use of a concept beyond its core use to match a new situation (Murphy, 1997; Tsoukas \& Chia, 2002). Finally, conceptual reframing demands reclassifying an object, or at least shifting emphasis from one class membership to another, so that a new view of it emerges (Bartunek, 1988; Bateson, 1972).

The characteristics of new knowledge creation discussed above have significant parallels with those associated with effective facilitated modelling practice. First, they both imply group interactions manifested through structured yet open (or dialogue-type) exchanges. Second, they require participants to adopt a reflective stance to deal with the task at hand. Third, they both involve socio-cognitive processes that focus on the articulation of conceptual distinctions about a problem. Despite these parallels, however, we still have limited empirical treatments of the impact of facilitated modelling on the production of new knowledge at the level of group interactions. There are some exceptions. Eden and his colleagues have examined the different ways group members share knowledge or 'change their minds' about complex issues (Ackermann \& Eden, 2011b; Shaw et al., 2003). These studies adopt a managerial cognition perspective, and suggest that some progress is being made in this area of the group decision and negotiation literature. However, despite their significance, the studies by Eden and colleagues rely on computer loggings of group members' contributions along with their timing, rather than on actual facilitated modelling interactions as they happen in a workshop setting. 
The notable exception is the work by Horlick-Jones and Rosenhead (2007), who use ethnographic methods to target, assist the deployment of, and evaluate a particular family of facilitated modelling approaches known as 'problem structuring methods' (Rosenhead \& Mingers, 2001). In particular, their use of ethnomethodology (Garfinkel, 1967; Heritage, 1984) to examine problem structuring workshops advances our understanding of the situated dynamics of group conversations in this setting. However, the group decision support aspects of the workshops studied by Horlick-Jones and Rosenhead tend to stay in the background and are thus overlooked, such as the role and impact of model-supported interactions. In the following sections we address this gap by bringing these aspects to the fore of our analysis. To this end, we adopt Tsoukas' (2009) knowledge creation framework as an analytical lens to empirically investigate under which conditions a facilitated modelling workshop is conducive to productive dialogue and thus new knowledge. That is, we will examine the extent to which group members interacting within a facilitated modelling workshop are able to engage relationally with one another, and the extent to which they create opportunities for reconceptualisation and new knowledge creation via conceptual combinations, expansions and reframing.

\section{Methodology}

We conducted a detailed, micro-level analysis of the conversations held by members of an Alternative Food Network (AFN) in the UK, referred to here as 'Sustain'. The group conversations took place during a 2-day workshop carried out as part of a larger facilitated modelling intervention undertaken between 2011 and 2012. AFNs aim to promote the quality, locality and sustainability of food production, distribution, and consumption. Local production, distribution, and consumption of food create opportunities for retaining economic value within the local community, supporting local diets and establishing socially embedded relationships between producers and consumers. Consumers purchase food at 'alternative food purchasing venues' (cf. Milestad, Bartel-Kratochvil, Leitner, \& Axmann, 2010) such as farmers' markets, box schemes, community supported agriculture initiatives, community gardens and short food supply chains (Ilbery \& Maye, 2005; Jones, Comfort, \& Hillier, 2004; King, 2008; Marsden, Banks, \& Bristow, 2000; Milestad et al., 2010; Sage, 2003). Often, such venues do not only offer sustainable food but also activities for education, training, and community building (Jarosz, 2000; King, 2008). In the case of Sustain, the range of products and services offered included: two agriculture sites (forestry and permaculture); a vegetable and fruit box scheme; a community garden; a catering service; an education service; and a community events service.

AFNs typically face constraints such as high production and distribution costs, competition with global market players that cause uncertainty that impinges on decision making, and inefficiencies in operational activities. In addition, work relations between AFN members can at times be hampered due to their different (and sometimes contrasting) perspectives, interests and goals, which can hinder effective collaboration and reaching agreements (Milestad et al., 2010). These characteristics were also evident in the case of Sustain. For example, those in charge of the different products and services would carry out their activities without an awareness of their impact on others' decisions and activities, or the need for intra-organisational coordination. Furthermore, there was frustration among AFN members regarding unproductive meetings and style 
of management, which was attributed to the lack of a shared mission and clear organisational roles and responsibilities. Finally, whilst the shorter-term future of Sustain was deemed relatively secure, their long-term prospects were considered less certain due to the on-going economic climate.

It is against the above background that Sustain arranged for an intervention to be carried out to redesign the organisation. Given that some members of Sustain had prior experience of the use of the Viable System Model (VSM) (Beer, 1984, 1985b) as an intervention approach in cooperatives, Sustain's management felt the VSM would also be helpful in this context. Although traditionally considered a 'hard' systems method (see, for example, Jackson, 2000), VSM can also be used as a facilitated modelling approach (Harnden, 1989), and this is how it was deployed in the intervention described below.

\subsection{Intervention approach and data collection}

VSM can be thought of as a meta-language that provides a template to map out the complexities of an organisation, and assess its long-term viability (for extensive treatments of the rationale underpinning the VSM see Beer, 1979, 1981, 1984, 1985a, b). For this purpose, the VSM is first used as a diagnostic, and subsequently as a design tool, in a facilitated process in which those involved critically examine their current organisation and performance. Diagnosing mostly involves rethinking the organisation using the different VSM elements, whereas designing requires that those involved build a model of the organisation as a viable system, namely, a system that is capable of constantly adapting to changes in the external environment while maintaining autonomy. Long-term viability is enhanced by ensuring appropriate balance between five systems (Beer, 1984): system 1 (S1) is composed of the autonomous operational units responsible for the basic work; system 2 (S2) deals with conflicts of interest between the operational units; system 3 (S3) optimises the interactions between the operational units; system 4 (S4) is responsible for the interaction with the external environment; and system 5 (S5) is responsible for closure, identity and ethos. Agreement on how to act and implement the VSM in practice typically results from active participation in the diagnosis and design process. VSM has been used to, for example, support the re-organisation of cooperatives and eco-villages (Walker, 1991; Espinosa and Walker, 2011; 2013); promote environmental sustainability (Espinosa et al, 2008); support educational development (Espinosa and Jackson, 2002); and analyse information processes in disaster response (Preece et al, 2012) -for a review of applications see Azadeh et al, (2012).

The main purpose of the intervention was to rethink Sustain as an organisation, using the VSM as a meta-language, with a view to identifying and understanding critical issues, and achieving joint agreements on actions to address them. The intervention was led by an external and experienced VSM facilitator, who gave us access to observe a 2day workshop undertaken as part of the intervention. The first author attended the workshop as a non-participant observer, and was allowed to audio-record the workshop on each day. The workshop audio recording was subsequently transcribed and this transcript, together with the observation notes taken during the workshop, represents our main source of data. 
The workshop was carried out with a group of 11 participants drawn from Sustain's management board, administration and finance office, and the different operational units responsible for delivering the aforementioned products and services. During the first day, the VSM was first introduced by the facilitator and then used to examine Sustain's current organisational structure and operations, and agree on a mission statement. Assisted by the facilitator, participants then built a model of Sustain as a viable system, which led to a set of preliminary ideas for addressing key issues. By the end of the first day, all five systems in Sustain's VSM had been broadly developed: System S1 was comprised of seven operational units: (i) 'food production-growing' (also known as 'Fresh', the name of the green site) is responsible for growing vegetables and fruit; (ii) 'food distribution' distributes food; (iii) 'kitchen-catering' mostly prepares and delivers food to cafes and events; (iv) 'community events' organises events for the local community; (v) 'training' provides opportunities for education; (vi) 'community garden' maintains recreational areas for the local community; and (vii) 'green space development' primarily maintains and develops forestry sites. System S2 (responsible for managing conflict between S1 operational units) would be implemented via regular meetings among 7 key individuals leading the operational units. Similarly, system S3 (responsible for managing interactions between S1 operational units) and system S4 (responsible for managing interactions with the external environment) would be implemented through regular meetings amongst designated workshop participants from the different operational units. Finally, system S5 (responsible for closure, identity and ethos) would be implemented via the Sustain's management board.

During the second day, those in charge of the different operational units (see above) were tasked to build individual VSMs of their respective units, and then present their results to the group. A lively discussion ensued, which led to the production of an action plan that included core activities to focus on during the following months, together with agreed responsible actors and deadlines.

Our involvement with the intervention ended at this point, although we maintained contact with the facilitator to find out how the whole intervention was progressing. Following the workshop, further e-mail communications with the facilitator and those responsible for the food distribution and green space development units indicated that workshop participants were working hard towards implementing the agreed action plan. In addition, an informal talk between the first author and five workshop participants confirmed a positive perception of the VSM workshop process and outputs.

\subsection{Data coding and analysis}

We used Tsoukas' (2009) conceptualisation of knowledge creation to guide our examination of the facilitated modelling interactions that took place within the workshop and captured in the transcribed audio recording. The focus on data from a single workshop is appropriate where the interest is on examining communicative interactions in depth, particularly those mediated by technological artefacts such as models (cf.Thomas, Sargent, \& Hardy, 2011; Tsoukas, 2009). The advantage of using audio recordings is that they can be replayed for close examination of important interactions during data analysis. The workshop audio recording and associated transcript, together with the observational notes made by the first author, enabled us to reconstruct how Sustain's VSM was built step-by-step by the workshop participants. 
The analytical steps described below are presented in a linear fashion, although the actual analysis involved several iterations between these steps.

The analysis sought to identify whether the participants engaged in productive dialogue, and whether this contributed to the creation of new knowledge useful to address the workshop tasks. To this end, we started our analysis by conducting a close and repeated examination of the workshop transcript and audio recording. This helped us identify interaction segments in which particular issues associated with different parts of Sustain's VSM were discussed. Next, we singled out segments in which making new conceptual distinctions was evident, i.e. explicit instances where a conceptual combination, conceptual expansion and/or conceptual reframing was made. This screening procedure resulted in the list of 17 shorter segments shown in Table 1, which became our main units of analysis.

\section{INSERT TABLE 1 ABOUT HERE}

Our preliminary analysis indicated variations in the novelty of knowledge produced within these segments. Specifically, discussions within various segments resulted in either new knowledge, shared knowledge, or old knowledge being maintained. To code the segments we first sensitised ourselves with Tsoukas' (2009) conceptual framework, and then looked into each segment in more detail. As already discussed in section 2, Tsoukas' (2009) framework posits that new knowledge is created when participants use communicative behaviours that reflect a relational, rather than calculated, engagement. To assess the occurrence of relational or calculated engagement in our data, we looked for operational treatments of these constructs in the literature. A useful operationalisation is provided by Thomas et al (2011), which distinguishes relational from calculated engagement in terms of how meanings are negotiated through particular communicative behaviours. For example, group members building on meanings proposed by others to produce alternative meanings typically signals a relational mode of engagement among those involved; on the other hand, group members dismissing or undermining the meanings proposed by others suggests a calculated mode of engagement. We also noted other behaviours in our data such as deploying expertise or invoking the VSM (or its elements) to legitimise particular meanings. By moving between our data and the literature we were able to establish the ten communicative behaviours shown in Table 2

\section{INSERT TABLE 2 ABOUT HERE}

Using these behaviours as a coding scheme, we coded each turn in the 17 interaction segments shown in Table 1, thus identifying whether participants engaged in relational or calculated engagement. To ensure coding reliability, an independent coder was used both to identify interaction segments that contained new distinctions, and code each segment. Whilst the number of relevant segments remained the same, there were minor disagreements regarding coding. In this case, we discussed the codes with the 
independent coder until an agreement was reached. The first author's deeper understanding of both Sustain and the VSM workshop helped resolve any discrepancies.

We then wrote summary narratives describing the dynamics of knowledge production for each interaction segment. By comparing these narratives and their associated communicative behaviours we identified 3 distinct patterns of group knowledge production: the generative pattern (9 segments) produced new knowledge; the collaborative pattern (6 segments) assembled common knowledge to produce shared knowledge; and the assertive pattern (2 segments) reproduced customary knowledge. In the final stage of our analysis, we sought to assess the role that model-supported interactions played within these patterns, as discussed in the findings.

\section{Findings}

In this section we first describe the three group knowledge production patterns identified in the analysis, and then the link between these patterns and the workshop products. To aid our discussion, we will illustrate each pattern with a representative interaction segment from our data.

\subsection{Generative pattern}

This pattern is characterised by participants (including the facilitator) engaging in relational behaviours that enabled them to inter-subjectively accept the new distinctions they made, and led to the creation of new knowledge that had action implications for Sustain. Additionally, model-supported interactions were highly visible in the majority of segments within this pattern (6 out of 9 segments).

To illustrate this pattern we draw on the group discussion about the issue of board members' participation in regular meetings (S1/G1), which had been previously identified as a communication mechanism to implement systems S3 and S4 within Sustain. The segment below opens by F (Facilitator) clarifying the need for weekly meetings between S3 and S4, whilst referring to the VSM drawn on the flip chart (turn 1). This need is then affirmed by P1 (Participant) (turn 2). Next (turn 3), F makes reference to a similar organisation, GreenCo (a pseudonym), where VSM had been used and similar meetings implemented, and proposes to do the same within Sustain. By referring to a previous VSM experience, F is doing two things. First, F deploys authority, based on the experience of using VSM with another organisation, to legitimise the way the VSM is being built, and the meanings associated with its constitutive systems. Second, F makes a new distinction via an analogy (a type of conceptual expansion). This new distinction is then challenged by $\mathrm{P} 1$, who states that board members are very busy with other activities (turn 4), which may create a possible conflict by posing restrictions to the effective organisation of the proposed meetings.

1 F The interaction between 3 and 4 ((S3 and S4)), it sounds to me like this is mainly gonna happen in these weekly meetings ((referring to the VSM on the flipchart)), ok?

2 P1 $\quad$ Yes

3 F So therefore you have the 7 people ((referring to the 7 Operational Units in the VSM)) plus you two ((the admin staff)) so it is gonna be everybody. In the GreenCo they have S3 and S4 meetings going on and the board represents the system outside and it is their job to monitor whatever is going 
on in the meetings. If something starts moving outside policy constraints they have the role to interfere. Ok so if you do it in that context...

$4 \quad$ P1 So it is board level, board members also do voluntary work, it is gonna be diary wise [...] I can see a possible conflict there, people are busy

Key: F - Facilitator; P - Participant. The use of an ellipsis in brackets (i.e. [...]) following a statement indicates that utterances by one or more participants have been edited out.

F then proposes a way to deal with this potential conflict (turn 5). Interestingly, P1 proposes an alternative way forward by making a new distinction (turn 6): he redefines the meaning of board members' participation in regular meetings by having access to minutes or recordings of the meetings (a conceptual reframing). P1 then invites others to comment on his proposal. P3 then builds on P1's proposal (turns 7 and 9) by recognising the challenge of getting board members to participate in regular meetings, and adding that any solution should be kept "nice and simple" like "bullet points" type minutes. Towards the end of the segment (turns 8, 10 and 11) there are affirmations by BM1 and BM2 (Board Members), as well as P3, regarding this new proposal.

$5 \quad$ F $\quad$ You could give them let's say a three day note to respond ((concerning regular meetings))

$6 \quad$ P1 What about providing them with minutes or recording? What do you think?

$\begin{array}{lll}7 & \text { P3 } & \text { I think what we have to do with the board situation is a capacity factor and a }\end{array}$ simple form of communication and the clearest would be weekly meetings and minutes. It becomes quite a challenge for them to join meetings...or a board representative is sent to the meetings...try to keep it nice and simple

8 BM2 Absolutely

$9 \quad$ P3 We know that the board does not have the capacity to attend things and it causes delays, so I think we don't want delays or to strain anybody further, so we should be able to respond easily and simply. I don't think like recording, just a bullet point ((minutes)) of what we discussed

10 BM1 Yes, a list of actions ((minutes))

11 P3 Yes this is sort of what we will do

Notes: F - Facilitator; P - Participant; BM - Board Member.

In sum, we can see that particular combinations of communicative behaviours, i.e., clarifying, inviting, proposing, challenging, building, and affirming helped workshop participants re-consider standard organisational practices and routines, and explore different ways to manage the issue of board members' participation in regular S3 and S4 meetings. Interestingly, F's deployment of authority during the discussion did not hinder the workshop participants' ability to make new distinctions in subsequent exchanges, which eventually culminated in the creation of a simple but new form to organise the meetings within Sustain. Within this interaction segment participants were able to self-distanciate and articulate two new distinctions that were inter-subjectively accepted, and had action implications for Sustain. Furthermore, model-supported interactions appeared to have had a positive effect on fostering self-distanciation and making new distinctions, as these occur after interacting with or referring to the VSM on the flip chart, or after interacting with the facilitator.

\subsection{Collaborative pattern}


Similar to the generative case, the collaborative pattern is also characterised by relational engagement. In contrast to the generative case, however, the collaborative pattern does not create 'new' knowledge. Instead, workshop participants share and build upon common knowledge to deal with particular issues and make progress. Highlyvisible model-supported interactions were also present in the majority of segments within this pattern (4 out of 6 segments).

The conversation about Sustain's primary activities (related to system S1) illustrates this pattern (S2/C1). In the segment below, participants attempt to unpack the different aspects associated with the 'food supply' primary activity, with a view to establishing the responsible operational units. The segment opens with $F$ building a model of Sustain's S1 on a flip chart, and inviting workshop participants to contribute (turn 1). P6 then proposes (turn 2) three key processes (production, processing, and distribution), which are subsequently affirmed by $\mathrm{F}$ and then transferred onto the model (turn 3). Next, P5 challenges the apparent independent operational role of the kitchen within the model (turn 4), which is affirmed by BM2 (turn 5).

$\begin{array}{ccc}1 & \text { F } & \begin{array}{l}\text { Let's start again with S1 ((building the VSM on flipchart))...so we had } \\ \text { food }\end{array} \\ 2 & \text { P6 } & \begin{array}{l}\text { Food production, distribution and processing, the kitchen processes } \\ \text { food, fresh ((site used for growing vegetables and fruit)) produces it } \\ \text { and local food distributes it }\end{array} \\ 3 & \text { F } & \begin{array}{l}\text { Ok, so we have } 3 \text { different things ((building the VSM on flipchart)) } \\ \text { [...] }\end{array} \\ 4 & \text { P5 } & \begin{array}{l}\text { I am not happy with that because the kitchen ((a unit within Sustain)) } \\ \text { plays too much of an independent operational role as a kitchen } \\ 5\end{array} \\ \text { BM2 } & \quad \text { Yes, you are right }\end{array}$

Notes: F - Facilitator; P - Participant; BM - Board Member. The use of an ellipsis in brackets (i.e. [...]) following a statement indicates that utterances by one or more participants have been edited out.

F then builds on P5's contribution, by developing an alternative meaning for the role of the kitchen (turn 6). P5's concern is reiterated by BM2 (turn 7), which prompts F to seek clarification whilst editing the model on the flip chart (turn 8). The relationship between production, processing, distribution, and the kitchen operation is reiterated and affirmed by participants in the following three exchanges (turns 9, 10, and 11). Next, P2 and P5 build on each other's views about the kitchen (turns 12 and 13). Notice how P5 makes a new distinction by combining the concepts 'kitchen' and 'catering' to create a new concept 'kitchen catering' (a conceptual combination), which is then affirmed by $\mathrm{F}$ (turn 14) and added to the model.

\begin{tabular}{ccl}
6 & F & $\begin{array}{l}\text { Depends on the level of recursion ((referring to the VSM)) } \\
\text { I would put it as P5 said, food production is one, and we want food } \\
\text { distribution as another. } \\
\text { ((editing VSM on flipchart)) growing and the internal processing as } \\
\text { well? }\end{array}$ \\
$\begin{array}{ccc}\text { BM2 } \\
9\end{array}$ & F & $\begin{array}{l}\text { BM2/P5 } \\
\text { Food distribution and then kitchen ((referring to the operational units } \\
\text { in the VSM)) }\end{array}$ \\
\hline
\end{tabular}




\begin{tabular}{lcl}
\hline 11 & ALL & $\begin{array}{l}\text { ((people agree)) } \\
12\end{array}$ \\
P2 & Kitchen is just for catering \\
13 & P5 & $\begin{array}{l}\text { Kitchen is a brand, kitchen catering is an operation } \\
\text { Ok ((building VSM on flipchart; kitchen catering is added as an } \\
\text { operational unit to the VSM)) }\end{array}$ \\
F
\end{tabular}

Notes: F - Facilitator; P - Participant; BM - Board Member. The use of an ellipsis in brackets (i.e. [...]) following a statement indicates that utterances by one or more participants have been edited out.

As illustrated by the preceding segment, those involved in the collaborative pattern engaged in a certain mix of communicative behaviours, i.e. inviting, clarifying, challenging, reiterating and building, that enabled a new distinction to emerge and be inter-subjectively accepted by those involved. The distinction in this case did not lead to brand new knowledge. Instead, as the segment above illustrates, common knowledge about food supply is shared and assembled by workshop participants. This led them to agree on 'kitchen catering' as constituting a new operational unit added to the VSM, which had action implications for Sustain. As in the generative case, model-supported interactions too appeared to have facilitated self-distanciation and the emergence of new distinctions among workshop participants.

\subsection{Assertive pattern}

This pattern is characterised by minimal cooperative behavior during group discussions that led to reproducing existing knowledge, rather than developing new knowledge or assembling common knowledge about the issues of concern. Surprisingly, the evidence suggests that model-supported interactions were used to fix meanings and/or positions, making these non-negotiable.

To illustrate this pattern we draw on the discussion about the issue of line management within the Sustain's VSM (S3/A1). In contrast to the previous two empirical illustrations, the segment below is characterised by polarised interactions between two contrasting positions about the need for line management in the VSM. One position, held by F, argued that the nature of the VSM implied little need for line management; whereas the other one, held in particular by P3, raised strong doubts about the appropriateness of not having a formal line management mechanism. Prior to the segment below, participants had sought to clarify with $\mathrm{F}$ whether line management issues are considered within the VSM built for Sustain. F then invokes the specific coordinating mechanisms within different systems (S2, S3 and S4) in the VSM in an attempt to reify their meaning, making them non-negotiable (turn 1). This is not intersubjectively accepted by P3, who challenges the implicit VSM-related assumption that there is no need for line management (turn 2).

$1 \quad \mathrm{~F} \quad[\ldots]$ about line management, it is different, you have these 7 people at the side ((referring to the VSM on the flipchart)) and not line managers because they have no authority to tell people what to do in the organisation, so the way that these people deal with the people inside there ((referring to the operational units in the VSM)), they will get information from S2, they will come back from S3 and S4 meetings and say to everybody else we are gonna do this, this and this and we decided this and then it will be their job to talk about that and put those things into action and there will be monitoring people [...] 

they are really good at covering their back. I think if you don't line manage then you got no supervision [...] how does somebody become accountable, how do you account for somebody, how do you sort of to say you have to do better, who says that?

Notes: F - Facilitator; P - Participant; BM - Board Member. The use of an ellipsis in brackets (i.e. [...]) following a statement indicates that utterances by one or more participants have been edited out.

In the exchanges that follow, the issue of line management is reiterated by P3 over several turns (turns 3, 5, 7, and 9). Importantly, F challenges P3's position by questioning the possibility of having issues within a small team (turn 4) and deploys authority based on his experience with small teams (turn 6), both of which in effect represent attempts to circumscribe the need for line management to the case of bigger rather than small teams (as implied in Sustain's VSM). A short exchange between BM2 and P3 follows, where the former reiterates the meaning of the implied roles and relationships between the different VSM operational units (turn 8), and the latter reiterates (again) the line management issue (turn 9). Towards the end of the segment $\mathrm{F}$ deploys authority by referring to the GreenCo experience (turn 10) with a view to legitimise his position, which is challenged by P3 (turn 11). The segment ends with P3 tabling the issue (turn 13).

3 P3 If it is a personal situation or a bit of bullying around the organisation or something, how is that dealt with?

$4 \quad \mathrm{~F} \quad$ This is a small team, 2 or 3 people. You are saying that there are issues within the team or 2 or 3 people

$5 \quad$ P3 No I am just saying

6 F Ok, I don't know... because when I work in teams that are that small I mean generally it works very well. You can say you have been really lazy this week, can you figure it out?

[...]

$\begin{array}{lll}7 & \text { P3 } & \text { I was talking about supervision or somebody is not doing what he should be }\end{array}$ doing. Can you say let's meet next week and talk about it, and see where you are and with minutes to see what has been done. I would like to see that in this model , so I am wondering whether there is that format [...]

8 BM2 [...] it is a more larger board than it was before and in that sense what I am hoping will happen is that individual members of the board will take on that supportive relationship with individual people and take on roles of backing up each one of these ((referring to the operational units in the VSM))

$9 \quad$ P3 Yes I understand. My question was what is the process to deal with it...[...]

10 F Well, what...in GreenCo for example they have weekly information packs, with like a burn out index...you can do anything. I think there are some human issues in every structure, it is just gonna be difficult because some people can be very difficult, you just have to work with it

11 P3 But you don't have a line manager in the system ((VSM))

12 F Yes, but you know...

13 P3 Yes, it is ok

Notes: F - Facilitator; P - Participant; BM - Board Member. The use of an ellipsis in brackets (i.e. [...]) following a statement indicates that utterances by one or more participants have been edited out. 
In sum, the exchanges above were all attempts to fix individual positions (e.g. those espoused by P3 and F). These attempts were encapsulated in a particular combination of communicative behaviours, i.e. reifying, challenging, deploying authority, reiterating, which deterred the possibility of the new distinction made by F (analogy - conceptual expansion in turn 10) to be accepted and new or common knowledge to be developed. The evidence thus suggests that a polarised reproduction of participants' existing knowledge about line management issues is likely to have taken place in this segment. Finally, model-supported interactions appeared to have been mostly one-sided, particularly to support F's position, they fail to address some of the workshop participants' concerns (e.g. P3) regarding the line management issue.

Of the total of 17 interaction segments comprising the generative and collaborative patterns illustrated above, we identified 15 segments in which it can be argued there was a (documented) link to the workshop products. These are shown in Table 3, where the patterns are listed against the issues discussed within each segment and the corresponding workshop product. In the majority of cases there were clear actions that followed the workshop. Table 3 also lists the two assertive patterns derived from our analysis, which had no action implications within or beyond the workshop. Overall, the evidence suggests that the facilitated modelling workshop was successful in helping participants develop and implement coordinated action, and that this was mostly associated with generative and collaborative conversational patterns that signified a productive dialogue among those involved.

\section{PLACE TABLE 3 ABOUT HERE}

\section{Discussion}

In this section we build from the preceding analysis to develop a tentative framework that shows how variations in what we call facilitated modelling practices -namely, the set of communicative behaviours and model-supported interactions displayed by those involved in a workshop- can enable or constrain the possibility of producing knowledge that has implications for action. Furthermore, the framework aims to provide both theoretical and practical insights into how certain facilitated modelling practices are more likely to enable a dialogue that is productive. We also explore how the empirical research presented here contributes to the effective conduct of facilitated modelling workshops.

\subsection{Dynamics of group knowledge production}

Figures 1 and 2 show how the intersection of particular communicative behaviours and model-supported interactions led to different dynamics of group knowledge production that have implications for action. The first dynamic (Figure 1) results from the adoption of a range of communicative behaviours: inviting, clarifying, proposing, building, affirming, and deploying authority (drawn from expertise, experience, or both) by the facilitator, and inviting, proposing, challenging, building, reiterating and affirming by the workshop participants. The adoption of these behaviours characterises a modality of interaction whereby those involved take active responsibility for their joint tasks and are open to mutual influence, referred to as relational engagement (Tsoukas 2009). This is 
in turn reinforced by model-supported interactions that enable those involved to expand, combine and reframe concepts, which helps to produce a generative or collaborative pattern that leads to new or shared knowledge with action implications. In the generative pattern illustrated in Section 4.1, a novel way to manage the board members' participation in meetings is developed incrementally in the give and take of a VSMbased discussion. Similarly, in the collaborative pattern illustrated in Section 4.2, common knowledge about food supply is shared and jointly articulated in the give and take of interaction. Because the knowledge developed led to action (see Table 3), it can be said, in Tsoukas' (2009) terms, that productive dialogue was achieved within both patterns.

The second dynamic (Figure 2) stems from the adoption of a different set of communicative behaviours: reifying, deploying authority, challenging and reiterating. These behaviours are associated with interactions that aim to maximise or protect individual gains, meanings or positions -that is, with a calculated engagement (Tsoukas 2009). The facilitator engages in reifying, challenging, and deploying authority, whereas workshop participants rely primarily on challenging and reiterating. This leads to a pattern of interaction where, instead of creating or sharing knowledge, there is the polarised reproduction of existing knowledge. In the assertive pattern illustrated in Section 4.3, the facilitator refers to his experience with, and knowledge of, VSM in other settings to assert that line management was not needed. By contrast, we see other participants (e.g. P3) reiterating their doubts time and time again about appropriateness of not having formal line management mechanisms. Furthermore, we see how the facilitator and workshop participants relate to the VSM to fix and demarcate the meaning of concepts about the line management issue. With no signs of (relational engagement) behaviours such as inviting or building, there is little room to combine or reframe meanings related to the line management issue. As a result, the issue is tabled and no action follows (see Table 3). In Tsoukas' (2009) terms, dialogue was unproductive within this pattern.

\subsection{Implications for the conduct of facilitated modelling workshops}

This study makes some specific contributions to the existing body of work on facilitated modelling within the group support literature. First, it provides a way to ground some of the more general prescriptions for facilitators that feature in this literature (Ackermann, 1996; Eden, 1990; Huxham \& Cropper, 1994; Kolfschoten, Hengst-Bruggeling, \& Vreede, 2007; Phillips \& Phillips, 1993; Taket, 2002; Visser, 2007) in more specific forms of interaction. For example, exhortations for facilitators to deploy interventions that "explicitly account for process and content issue together" (Eden 1990, p.49), "make substantive contributions to a consultancy process in a way that is facilitative" (Huxham and Cropper 1994, p.8), and help a group "maintain its task orientation" (Phillips and Phillips 1993, p.542), fail to address the nuances whereby such advice has to be enacted through communicative behaviours during interaction. Similarly, more specific recommendations such as 'asking difficult and sometimes obvious questions' (Ackermann 1997) or 'handing contributions back in changed form' (Philips and Phillips 1993) do not take into account the idea that asking difficult or obvious questions' can take a number of different forms including inviting, clarifying, and challenging, whereas 'handing back in changed form' can range from building to proposing. Even 'scripts' that provide detailed instructions to facilitators on what to say 
to the group in order to achieve intended workshop products (e.g. Ackermann, Andersen, Eden, \& Richardson, 2011; De Vreede, Briggs, \& Kolfschoten, 2006; Kolfschoten, Briggs, de Vreede, Jacobs, \& Appelman, 2006; Kolfschoten, Grünbacher, \& Briggs, 2011), do not consider the different ways in which such instructions can be communicated. Our study provides insights into the types of specific communicative behaviours — such as building, challenging, affirming, etc. - that can enact and sustain these general and more specific prescriptions.

Second, our study highlights how the same communicative behaviour may lead to quite different outcomes depending on the interaction context in which it is used. For example, workshop participants' use of challenging and reiterating in response to the facilitator's attempts to build the model of Sustain's S1 (see Section 4.2) involved a relational engagement by both parties. In contrast, their use of the same communicative behaviours in response to the facilitator's attempts to dismiss the issue of line management (see Section 4.3) represented a defensive manoeuvre. Similarly, the use of expertise and experience as a form of authority by the facilitator was not always successful during model building. In summary, the impact of a particular communicative behaviour depends on who is employing it, when, and with what purpose.

Finally, in showing that the same workshop produced three group knowledge production patterns, depending on the way in which particular communicative behaviours and model-supported interactions were juxtaposed over time, we rebalance the tendency in the facilitated modelling literature to categorize a particular workshopbased intervention as either successful or not. Our research shows that, from the perspective of group knowledge production advanced by Tsoukas (2009) and at the micro-level of analysis, the same workshop can exhibit both successful and unsuccessful facilitated modelling practices. The existing literature has little to say about the impact of communicative behaviours and model-supported interactions as they intermingle over time within a particular workshop. Instead, this literature tends to offer general prescriptions on how to design and run a successful workshop. This focus, however, does not show the ways in which a workshop is brought into being through the interaction of communicative behaviours and model-supported interactions.

\section{Conclusion}

This exploratory research reported in this paper provides a complimentary departure from mainstream facilitated modelling literature that has emphasised the use of holistic or a macro-level lens to evaluate model-supported interventions via action research (e.g. Eden, 1992, 1995), case studies (Ackermann, Franco, Gallupe, \& Parent, 2005; Franco, 2008) or surveys (Midgley et al., 2012; Rouwette, Vennix, \& Felling, 2009). By using Tsoukas' (2009) conceptualisation of new knowledge creation and a micro-level analysis, we were able to provide empirical evidence of the impact of particular facilitated modelling practices on the group knowledge production process. Our analyses enabled us to develop a conceptual model (see Figures 1 and 2) that offers a more nuanced approach to our understanding of what happens within a facilitated modelling environment from the perspective of group knowledge production. The insights derived from this framework contribute towards theory elaboration about the nature of facilitated modelling interactions in practice. The framework also 
demonstrates the importance of understanding which facilitated modelling practices enhance or constrain group knowledge production within workshops,

Our research has some obvious limitations. First, in order to conduct a micro-level analysis of facilitated modelling within its context of immediate use, and with the resources we had at our disposal, we had to focus on a single workshop. The downside was that we were unable to study other workshops. Second, we only analysed the group discussion in the workshop due to the impossibility of video recording the workshop. Finally, we distinguished Sustain's members from the facilitator for analytical purposes, but we acknowledge that there were differences within the former.

Notwithstanding these limitations, there is considerable potential for further research using the knowledge-perspective and micro-level lens adopted here. One aspect that invites further consideration is the conditions conducive to generative or collaborative group knowledge production patterns. We have identified that both patterns are underpinned by group interactions that resemble a relational mode of engagement, yet only the generative pattern creates new knowledge. Why is this so? Recent empirical studies of strategic decision making suggest that the characteristics of the issue under discussion influences how group interactions unfold over time (e.g. Liu \& Maitlis, 2014). Thus, for example, if an issue calls for the redesign of a system or its parts, then a generative pattern may follow. By contrast, if an issue can be dealt with by just adapting the current system then a collaborative pattern is more likely to ensue. Further research with such a focus may help to account for whether generative or collaborative group knowledge production patterns are observed in facilitated modelling workshops.

There are also opportunities for a more explicit consideration of the impact of the use of expertise and experience by the facilitator within a workshop. The facilitated modelling literature is divided on this aspect. Some scholars (e.g. Phillips \& Phillips, 1993) argue that the injection of substantive contributions to the discussion content based on experience or expertise should be avoided at all costs. Others (e.g. Huxham \& Cropper, 1994) have an opposing view, and have argued that substantive inputs by the facilitator, when made in a non-authoritative manner, can be advantageous for the interaction. Our findings show that the use of expertise and experience (as a form of deploying authority) had sometimes positive and other times negative consequences for the interaction, and so more research in this direction is needed to assess the appropriateness of this communicative behaviour. The impact of the client-facilitator relationship (Eden \& Sims, 1979) on workshop interactions would represent a useful complementary focus of this stream of future work.

Finally, there is a need for more micro-level analyses of other facilitated modelling workshops to examine what is that facilitators and workshop participants actually do as they interact in a model-supported discussion. Although we have identified certain facilitated modelling practices linked to generative and collaborative patterns that resemble a relational mode of engagement among those involved, as well as to assertive patterns that resemble a calculative mode of engagement among those involved, this is not to suggest in any way that these are the only facilitated modelling practices that can be used. Further exploration of these practices is needed for the case of different facilitated modelling approaches, different facilitators, and different organisational 
contexts, so that useful generalizations about the effective conduct of facilitated modelling workshops can be developed.

\section{References:}

Ackermann, F. 1996. Participant's Perceptions on the Role of Facilitators Using Group Decision Support Systems. Group Decision and Negotiation, 5(1): 93-112.

Ackermann, F., Andersen, D. F., Eden, C., \& Richardson, G. P. 2011. Scriptsmap: a tool for designing multi-method policy-making workshops. OMEGA: The International Journal of Management Science, 39(4): 427-434.

Ackermann, F., \& Eden, C. 1994. Issues in Computer and Non-computer Supported GDSSs. Decision Support Systems, 12(4,5): 381-390.

Ackermann, F., \& Eden, C. 2001. Contrasting Single User and Networked Group Decision Support Systems for Strategy Making. Group Decision and Negotiation, 10(1): 47-66.

Ackermann, F., \& Eden, C. 2005. Using Causal Mapping with Group Support Systems to Elicit an Understanding of Failure in Complex Projects: Some Implications for Organizational Research. Group Decision and Negotiation, 14(5): 355-376.

Ackermann, F., \& Eden, C. 2010. Strategic Options Development and Analysis. In M. Reynolds, \& S. Holwell (Eds.), Systems Approaches to Managing Change: A Practical Guide: 135-190. London: Springer.

Ackermann, F., \& Eden, C. 2011a. Making Strategy: Mapping out strategic success (2nd ed.). London: Sage.

Ackermann, F., \& Eden, C. 2011b. Negotiation in Strategy Making Teams: Group Support Systems and the Process of Cognitive Change. Group Decision and Negotiation, 20(3): 293-314.

Ackermann, F., Franco, L. A., Gallupe, B., \& Parent, M. 2005. Group Support Systems for Multi-organizational Collaboration: Reflections on process and content. Group Decision and Negotiation, 14(4): 307-331.

Andersen, S. M., \& Chen, S. 2002. The relational self: An interpersonal social-cognitive theory. Psychological Review, 109: 619-645.

Bana e Costa, C., Lourenço, J., Oliveira, M., \& Bana e Costa, J. 2013. A Sociotechnical Approach for Group Decision Support in Public Strategic Planning: The Pernambuco PPA Case. Group Decision and Negotiation: 1-25.

Barrett, F. J. 1999. Knowledge creating as dialogic accomplishment: A constructionist perspective. In A. Montuori, \& R. E. Purser (Eds.), Social Creativity, Vol. 1: 133-151. Cresskill, NJ: Hampton Press.

Bartunek, J. M. 1988. The dynamics of personal and organizational reframing. In R. E. Quinn, \& K. S. Cameron (Eds.), Paradox and Transformation: 137-162. Cambridge, MA: Ballinger.

Bateson, G. 1972. Steps to an Ecology of Mind. Northvale, NJ.: Jason Aronson.

Bechky, B. A. 2003. Sharing meaning across occupational communities: The transformation of understanding on a production floor. Organization Science, 14(3): 312-330.

Beer, S. 1979. The Heart of Enterprise. Chichester: John Wiley \& Sons, Ltd.

Beer, S. 1981. Brain of the Firm. Chichester: John Wiley \& Sons Ltd. 
Beer, S. 1984. The viable system model: its provenance, development, methodology and pathology. Journal of the Operational Research Society, 35(1): 7-25.

Beer, S. 1985a. Designing the System for Organizations. Chichester: Wiley.

Beer, S. 1985b. Diagnosing the System. Chichester: John Wiley \& Sons Ltd.

Benner, P. 1994. The role of articulation in understanding practice and experience as sources of knowledge in clinical nursing. In. J. Tully, e. P. i. a. A. o. P. C. University, \& C. Press, UK, 136-155. (Eds.), Philosophy in an Age of Pluralism: 136-155. Cambridge: Cambridge University Press.

Bohm, D. 1996. On Dialogue. London: Routledge.

Cronin, K., Midgley, G., \& Jackson, L. 2014. Issues Mapping: A problem structuring method for addressing science and technology conflicts European Journal of Operational Research, 233(1): 145-158.

Cross, S. E., Morris, M. A. L., \& Gore, J. S. 2002. Thinking about oneself and others: The relational-interdependent self-construal and social cognition. Journal of Personality and Social Psychology, 82(3): 399-418.

Cushman, M., \& Rosenhead, J. 2004. Planning in the Face of Politics: reshaping children's health services in inner London. In F. Sainfort, M. Brandeau, \& W. Pierskalla (Eds.), Handbook of OR/MS Applications in Health Care. Boston, MA: Kluwer.

Darling, T., Mumpower, J., Rohrbaugh, J., \& Vari, A. 1999. Negotiation Support for Multi-Party Resource Allocation: Developing Recommendation for Decreasing Transportation-Related Air Pollution in Budapest. Group Decision and Negotiation, 8(1): 51-75.

De Vreede, G. J., Briggs, R. O., \& Kolfschoten, G. L. 2006. ThinkLets: a pattern language for facilitated and practitioner-guided collaboration processes. International Journal of Computer Applications in Technology, 25(2/3): 140154.

Eden, C. 1990. The Unfolding Nature of Group Decision Support: two dimensions of skill. In C. Eden, \& J. Radford (Eds.), Tackling Strategic Problems: the role of group decision support 48-52. London: Sage.

Eden, C. 1992. A Framework for Thinking About Group Decision Support Systems. Group Decision and Negotiation, 1: 199-218.

Eden, C. 1995. On Evaluating the Performance of "Wide-band" GDSS's. European Journal of Operational Research, 81(2): 302-311.

Eden, C., \& Ackermann, F. 2001. SODA: the principles. In J. Rosenhead, \& J. Mingers (Eds.), Rational Analysis for a Problematic World Revisited: problem structuring methods for complexity, uncertainty and conflict: 21-41. Chichester: Wiley.

Eden, C., \& Ackermann, F. 2013. 'Joined-Up’ Policy-Making: Group Decision and Negotiation Practice. Group Decision and Negotiation: 1-17.

Eden, C., \& Sims, D. 1979. On the Nature of Problems in Consulting Practice. OMEGA: The International Journal of Management Science, 7(2): 119-127.

Edmondson, A. C. 2002. The local and variegated nature of learning in organizations: A group-level perspective. Organization Science, 13(2): 128-146.

Franco, L. A. 2006. Forms of Conversation and Problem Structuring Methods: a conceptual development. Journal of the Operational Research Society, 57(7): 813-821. 
Franco, L. A. 2008. Facilitating Collaboration with Problem Structuring Methods: a case of an inter-organisational construction partnership. Group Decision and Negotiation, 17(4): 267-286.

Franco, L. A. 2013. Rethinking Soft OR interventions: Models as boundary objects. European Journal of Operational Research, 231(3): 720-733.

Franco, L. A., \& Montibeller, G. 2010. Facilitated Modelling in Operational Research (Invited Review). European Journal of Operational Research, 205(3): 489500.

Franco, L. A., \& Montibeller, G. 2011. 'On-the-Spot' Modelling and Analysis: the facilitated modelling approach. In J. J. Cochran, L. A. Cox Jr, P. Keskinocak, J. P. Kharoufeh, \& J. C. Smith (Eds.), Wiley Encyclopedia of Operations Research and Management Science. New York: Wiley.

Franco, L. A., \& Rouwette, E. A. J. A. 2011. Decision Development in Facilitated Modelling Workshops European Journal of Operational Research, 212(1): 164-178.

Friend, J. 2001. The Strategic Choice Approach. In J. Rosenhead, \& J. Mingers (Eds.), Rational Analysis for a Problematic World Revisited: problem structuring methods for complexity, uncertainty and conflict: 115-149. Chichester: Wiley.

Friend, J., \& Hickling, A. 2005. Planning Under Pressure: The Strategic Choice Approach (3rd ed.): Elsevier.

Garfinkel, H. 1967. Studies in Ethnomethodology. Englewood Cliffs, NJ: PrenticeHall.

Gratton, L., \& Ghoshal, S. 2002. Improving the quality of conversations Organizational Dynamics, 31(3): 209-223.

Hampton, J. A. 1997. Emergent attributes in combined concepts. In T. N. Ward, S. M. Smith, \& J. Vaid (Eds.), Creative Thought: 83-110. Washington DC: American Psychological Association.

Hargadon, A. B. 2003. How Breakthroughs Happen. Boston, MA: Harvard Business School Press.

Hargadon, A. B., \& Sutton, R. I. 1997. Technology brokering and innovation in a product development firm. Administrative Science Quarterly, 42: 716-749.

Harnden, R. 1989. Outside and then: an interpretive approach to the VSM. In R. Espejo, \& R. Harnden (Eds.), The Viable System Model: 383-404. Chichester: John Wiley \& Sons Ltd. .

Heritage, J. 1984. Garfinkel and Ethnomethodology. Cambridge: Polity.

Horlick-Jones, T., \& Rosenhead, J. 2007. The Uses of Observation: combining problem structuring methods and ethnography. Journal of the Operational Research Society, 58(5): 588-601.

Huxham, C., \& Cropper, S. 1994. From Many to One and Back: an exploration of the components of facilitation. OMEGA, 22(1): 1-11.

Ilbery, B., \& Maye, D. 2005. Food supply chains and sustainability: evidence from specialist food producers in the Scottish/English borders. Land Use Policy, 22: 331-344.

Isaacs, W. 1999. Dialogue and the Art of Thinking Together. New York: Currency. Jackson, M. 2000. Systems Approaches to Management. New York: Kluwer.

Jarosz, L. 2000. Understanding agri-food networks as social relations. Agriculture and Human Values, 17: 279-283. 
Jones, P., Comfort, D., \& Hillier, D. 2004. A case study of local food and its routes to market in the UK. British Food Journal, 106: 328-335.

Keys, P. 2007a. Knowledge Work, Design Science and Problem Structuring Methodologies. Systems Research and Behavioral Science, 24: 523-535.

Keys, P. 2007b. Reducing the process lacuna in Operational Research by taking a knowledge work perspective. Systems Research and Behavioral Science, 24: 285-296.

King, C. A. 2008. Community Resilience and Contemporary Agri-Ecological Systems: Reconnecting people and food, and people with people. Systems Research and Behavioural Science, 25: 11-224.

Kogler, H. H. 1996. The Power of Dialogue. Cambridge, MA: MIT Press.

Kolfschoten, G., Hengst-Bruggeling, M., \& Vreede, G.-J. 2007. Issues in the Design of Facilitated Collaboration Processes. Group Decision and Negotiation, 16(4): 347-361.

Kolfschoten, G. L., Briggs, R. O., de Vreede, G. J., Jacobs, P. H. M., \& Appelman, J. H. 2006. Conceptual foundation of the ThinkLet concept for collaboration engineering. International Journal of Human Computer Studies, 64(7): 611621.

Kolfschoten, G. L., Grünbacher, P., \& Briggs, R. O. 2011. Modifiers for Quality Assurance in Group Facilitation. Group Decision and Negotiation, 20: 685-705.

Liu, F., \& Maitlis, S. 2014. Emotional Dynamics and Strategizing Processes: A Study of Strategic Conversations in Top Team Meetings. Journal of Management Studies, 51(2): 202-234.

Luckmann, T. 1990. Social communication, dialogue and conversation. In i. Markova, \& K. Foppa (Eds.), The Dynamics of Dialogue: 45-61. Hemel Hempstead: Harvester Wheatsheaf.

Marsden, T., Banks, J., \& Bristow, G. 2000. Food Supply Chain Approaches: Exploring their role in rural development. Sociologia Ruralis, 40(4): 424-438.

Mengis, J., \& Eppler, M. J. 2008. Understanding and Managing Conversations from a Knowledge Perspective: An Analysis of the Roles and Rules of Face-to-face Conversations in Organizations. Organization Studies, 29(10): 1287-1313.

Merleau-Ponty, M. 1962. Phenomenology of Perception [Translated by C. Smith]. London: Routledge.

Midgley, G., Cavana, R., Brocklesby, J., Foote, J., Ahuriri-Drscoll, A., \& Wood, D. 2012. Towards a New Framework for Evaluating Systemic Problem Structuring Methods. European Journal of Operational Research.

Milestad, R., Bartel-Kratochvil, R., Leitner, H., \& Axmann, P. 2010. Being close: The quality of social relationships in a local organic cereal and bread network in Lower Austria. Journal of Rural Studies, 26: 228-240.

Möllering, G. 2006. Trust: Reason, Routine, Reflexivity. Amsterdam.: Elsevier.

Morton, A., Ackermann, F., \& Belton, V. 2003. Technology-driven and Model-driven Approaches to Group Decision Support: focus, research philosophy and key concepts. European Journal of Information Systems, 12(2): 110-126.

Murphy, G. L. 1997. Polysemy and the creation of novel meanings. In T. N. Ward, S. M. Smith, \& J. Vaid (Eds.), Creative Thought: 235-266. Washington DC: American Psychological Association.

Nonaka, I. G., \& Takeuchi, H. 1995. The Knowledge-Creating Company. New York: Oxford University Press. 
Nonaka, I. G., Toyama, R., \& Byosiere, P. 2001. A theory of organizational knowledge creation: Understanding the dynamic process of creating knowledge. In M. D. Dierkes, A. B. Antal, J. Child, \& I. G. Nonaka (Eds.), Handbook of Organizational Learning and Knowledge: 491-517. Oxford: Oxford University Press.

Phillips, L. 2007. Decision Conferencing. In W. Edwards, R. Miles Jr, \& D. von Winterfeldt (Eds.), Advances in Decision Analysis: from foundations to applications: 375-399. New York: Cambridge University Press.

Phillips, L., \& Bana e Costa, C. A. 2007. Transparent Prioritisation, Budgeting, and Resource Allocation with Multi-Criteria Decision Analysis and Decision Conferencing. Annals of Operations Research, 154(1): 51-68.

Phillips, L., \& Phillips, M. 1993. Facilitated Work Groups: theory and practice. Journal of Operational Research Society, 44(6): 533-549.

Rosenhead, J., \& Mingers, J. (Eds.). 2001. Rational Analysis for a Problematic World Revisited: problem structuring methods for complexity, uncertainty and conflict. Chichester: Wiley.

Rouwette, E. A. J. A. 2011. Facilitated modelling in strategy development: Measuring the impact on communication, consensus and commitment Journal of the Operational Research Society, 62(5): 879-887.

Rouwette, E. A. J. A., Bastings, I., \& Blokker, H. 2011a. A comparison of Group Model Building and Strategic Options Development and Analysis. Group Decision and Negotiation, 20(6): 781-803.

Rouwette, E. A. J. A., Korzilius, H., Vennix, J. A. M., \& Jacobs, E. 2011b. Modeling as persuasion: The impact of group model building on attitudes and behavior. System Dynamics Review, 27(1): 1-21.

Rouwette, E. A. J. A., \& Vennix, J. A. M. 2009. Group model building. In R. E. Meyers (Ed.), Encyclopedia of Complexity and Systems Science: 4474 - 4486. Heidelberg: Springer Verlag.

Rouwette, E. A. J. A., Vennix, J. A. M., \& Felling, A. J. A. 2009. On Evaluating the Performance of Problem Structuring Methods: An attempt at formulating a conceptual model. Group Decision and Negotiation, 18(6): 567-587.

Sage, C. 2003. Social embeddedness and relations of regard: alternative 'good food' networks in south-west Ireland. Journal of Rural Studies, 19: 47-60.

Sawyer, R. K. 2007. Group Genius. New York: Basic Books.

Shaw, D., Ackermann, F., \& Eden, C. 2003. Approaches to Sharing Knowledge in Group Problem Structuring. Journal of the Operational Research Society, 54(9): 936-948.

Taket, A. 2002. Facilitation: some contributions to theorising the practice of operational research. Journal of the Operational Research Society, 53(2): 126-136.

Thomas, R., Sargent, L. D., \& Hardy, C. 2011. Managing Organizational Change: Negotiating Meaning and Power-Resistance Relations. Organization Science, 22(1): 22-41.

Tschang, F. T. 2007. Balancing the tensions between rationalization and creativity in the video games industry. Organization Science, 18: 989-1005.

Tsoukas, H. 2003. Do we really understand tacit knowledge? In M. Easterby-Smith, \& M. A. Lyles (Eds.), Handbook of Organizational Learning and Knowledge: 410-427. Oxford: Blackwell. 
Tsoukas, H. 2009. A Dialogical Approach to the Creation of New Knowledge in Organizations. Organization Science, 20(6): 941-957.

Tsoukas, H., \& Chia, R. 2002. On organizational becoming: Rethinking organizational change. Organization Science, 13(5): 567-582.

Vennix, J. A. M. 1995. Building consensus in strategic decision making. Insights from the process of group model building. Group Decision and Negotiation, 4: 335 355.

Visser, M. 2007. System dynamics and group facilitation: Contributions from communication theory. System Dynamics Review, 23(4): 453-463.

Walton, D. N. 1998. The New Dialectic: conversational contexts of argument. Toronto: University of Toronto Press.

Walton, D. N. 2000. The place of dialogue theory in logic, computer science and communication studies. Synthese, 123: 327-346.

Walton, D. N. 2006. Fundamentals of Critical Argumentation. New York: Cambridge University Press.

White, L. 2009. Understanding Problem Structuring Methods Interventions. European Journal of Operational Research, 99(3): 823-833.

Yankelovich, D. 1999. The Magic of Dialogue: turning conflict into cooperation. New York: Simon and Schuster. 
Cite as: Tavella, E., \& Franco, L. A. 2014. Dynamics of group knowledge production in facilitated modelling workshops: An exploratory study (in press). Group Decision and Negotiation. (in press). 10.1007/s10726-014-9398-

Table 1: List of interaction segments identified for analysis

\begin{tabular}{|c|c|c|}
\hline Segment & Issue discussed & Label \\
\hline 1 & $\begin{array}{l}\text { Board members' participation in regular meetings in order to } \\
\text { strengthen the relationships between the actors and board } \\
\text { members of Sustain. }\end{array}$ & $\mathrm{S} 1 / \mathrm{G} 1$ \\
\hline 2 & $\begin{array}{l}\text { Identifying the Operational Units within Sustain - focus on } \\
\text { 'kitchen'. }\end{array}$ & $\mathrm{S} 2 / \mathrm{C} 1$ \\
\hline 3 & $\begin{array}{l}\text { Identifying how to carry out line management within the } \\
\text { VSM. }\end{array}$ & S3/A1 \\
\hline 4 & $\begin{array}{l}\text { Dealing with conflicts of interest between the Operational } \\
\text { Units and monitor the external environment. }\end{array}$ & $\mathrm{S} 4 / \mathrm{G} 2$ \\
\hline 5 & $\begin{array}{l}\text { Involve the board members in operational activities and } \\
\text { improve information sharing. }\end{array}$ & S5/G3 \\
\hline 6 & Identifying performance indicators within Sustain. & S6/G4 \\
\hline 7 & Identifying how to carry out S4 functions within Sustain. & S7/G5 \\
\hline 8 & Understanding budgetary and administrative matters. & S8/G6 \\
\hline 9 & Determining the wages for admin staff within Sustain. & S9/G7 \\
\hline 10 & $\begin{array}{l}\text { Understanding the importance of funding and marketing } \\
\text { within the VSM. }\end{array}$ & S10/G8 \\
\hline 11 & $\begin{array}{l}\text { Understanding S5 within the Operational Unit ‘community } \\
\text { garden'. }\end{array}$ & S11/G9 \\
\hline 12 & Formulating the mission statement of Sustain. & $\mathrm{S} 12 / \mathrm{C} 2$ \\
\hline 13 & $\begin{array}{l}\text { Identifying the Operational Units within Sustain - focus on } \\
\text { 'training' and 'community events'. }\end{array}$ & $\mathrm{S} 13 / \mathrm{C} 3$ \\
\hline 14 & $\begin{array}{l}\text { Identifying the Operational Units within Sustain - focus on } \\
\text { 'food production and growing' and 'food distribution'. }\end{array}$ & $\mathrm{S} 14 / \mathrm{C} 4$ \\
\hline 15 & $\begin{array}{l}\text { Identifying the Operational Units within Sustain - focus on } \\
\text { green space development'. }\end{array}$ & $\mathrm{S} 15 / \mathrm{C} 5$ \\
\hline 16 & Identifying how to set up policy procedures within Sustain. & S16/C6 \\
\hline 17 & Identifying the Operational Units within Sustain. & S17/A2 \\
\hline
\end{tabular}


Cite as: Tavella, E., \& Franco, L. A. 2014. Dynamics of group knowledge production in facilitated modelling workshops: An exploratory study (in press). Group Decision and Negotiation. (in press). 10.1007/s10726-014-9398-

Table 2: Communicative behaviours- adapted from Thomas et al. (2011)

\begin{tabular}{|c|c|}
\hline Code & Description \\
\hline Inviting & $\begin{array}{l}\text { Statements that encourage participation by } \\
\text { other group members in negotiation of } \\
\text { meanings }\end{array}$ \\
\hline Proposing & Statements that introduce a new meaning \\
\hline Affirming & $\begin{array}{l}\text { Statements that agree with alternative } \\
\text { meanings proposed by other group members }\end{array}$ \\
\hline Clarifying & Questions that open up negotiation of meaning \\
\hline Building & $\begin{array}{l}\text { Statements that engage with, elaborate, and } \\
\text { develop alternative meanings proposed by } \\
\text { other group members }\end{array}$ \\
\hline Dismissing & $\begin{array}{l}\text { Statements that serve to rebuff or ignore } \\
\text { alternative meanings proposed by other group } \\
\text { members }\end{array}$ \\
\hline $\begin{array}{l}\text { Deploying } \\
\text { authority }\end{array}$ & $\begin{array}{l}\text { Statements that contain directives that } \\
\text { eliminate alternative meanings proposed by } \\
\text { other group members, or refer to superior } \\
\text { knowledge or expertise to justify the } \\
\text { legitimacy of a proposed meaning, }\end{array}$ \\
\hline Reifying & $\begin{array}{l}\text { Statements that invoke concepts, processes or } \\
\text { objects (e.g. models) to represent a particular, } \\
\text { non-negotiable meaning }\end{array}$ \\
\hline Challenging & $\begin{array}{l}\text { Statements that reject or critique alternative } \\
\text { meanings proposed by other group members }\end{array}$ \\
\hline Reiterating & Statements that return to and repeat meanings \\
\hline
\end{tabular}


Cite as: Tavella, E., \& Franco, L. A. 2014. Dynamics of group knowledge production in facilitated modelling workshops: An exploratory study (in press). Group Decision and Negotiation. (in press). 10.1007/s10726-014-9398-

Table 3: Link between patterns and (documented) workshop products

\begin{tabular}{|c|c|c|}
\hline Segment & Pattern & Workshop products \\
\hline $\mathrm{S} 1 / \mathrm{G} 1$ & Generative & $\begin{array}{l}\text { Participants agree on meeting again four days after the workshop with } \\
\text { the board members. The aim is to involve board members in regular } \\
\text { S3-S4 meetings. }\end{array}$ \\
\hline $\mathrm{S} 4 / \mathrm{G} 2$ & Generative & $\begin{array}{l}\text { Participants agree on meeting again four days after the workshop. The } \\
\text { aim is to organise regular S3-S4 meetings. }\end{array}$ \\
\hline S5/G3 & Generative & $\begin{array}{l}\text { Participants agree on meeting again four days after the workshop and } \\
\text { ask the board members for their knowledge and expertise profiles. }\end{array}$ \\
\hline S6/G4 & Generative & $\begin{array}{l}\text { Participants P3 and P5 agree to be added to S3 in the VSM on the } \\
\text { flipchart as responsible for collecting performance indicators. }\end{array}$ \\
\hline S7/G5 & Generative & Participants agree to conduct SWOT and PDCA analysis. \\
\hline S8/G6 & Generative & $\begin{array}{l}\text { Administrative staff member agrees on setting up the user login and } \\
\text { carrying out staff training the week after the workshop. Budget } \\
\text { allocation is added as a priority activity to the action plan. }\end{array}$ \\
\hline S9/G7 & Generative & $\begin{array}{l}\text { Participants agree on adding food cost recovery as a priority activity } \\
\text { to the action plan, all actors are responsible. }\end{array}$ \\
\hline S10/G8 & Generative & $\begin{array}{l}\text { Participant P1 puts funding and marketing in the meta-system of his } \\
\text { VSM; funding and marketing are added as S3-S4 functions to the } \\
\text { VSM of Sustain; and budgeting and marketing are added to the action } \\
\text { plan. }\end{array}$ \\
\hline S11/G9 & Generative & $\begin{array}{l}\text { Participant P6 understands what constitutes S5 within 'community } \\
\text { garden' and that he is responsible for ensuring its proper functioning }\end{array}$ \\
\hline $\begin{array}{l}\text { S2/C1; } \\
\text { S13/C3; } \\
\text { S14/C4; } \\
\text { S15/C5 }\end{array}$ & Collaborative & $\begin{array}{l}\text { Participants agree on contributions to model content (Fig. 1a): } \\
\text { 'kitchen-catering' (S2/C1); 'training' and 'community events' } \\
\text { (S13/C3); 'food production-growing: fresh' and' food distribution' } \\
\text { (S14/C4); and 'green space development' (S15/C5) are added as } \\
\text { operational units to the VSM. }\end{array}$ \\
\hline $\mathrm{S} 12 / \mathrm{C} 2$ & Collaborative & Group agrees on mission statement for Sustain. \\
\hline S16/C6 & Collaborative & Participants agree on using QA-system. \\
\hline S3/A1 & Assertive & No agreements surfaced \\
\hline S17/A2 & Assertive & No agreements surfaced \\
\hline
\end{tabular}


Figure 1: Dynamics of group knowledge production: Generative and collaborative patterns

\section{FACILITATED MODELLING PRACTICES}
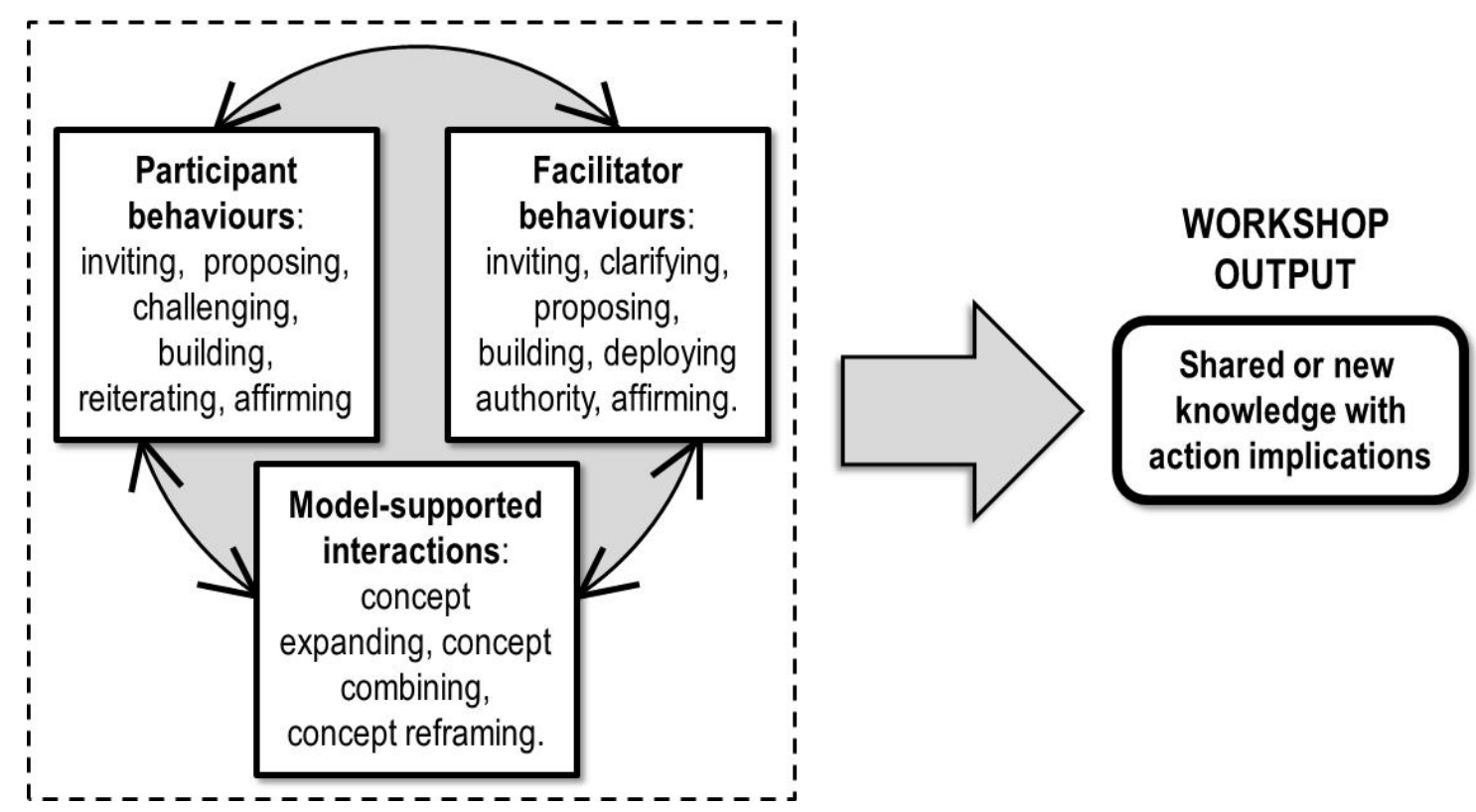
Figure 2: Dynamics of group knowledge production: Assertive pattern

\section{FACILITATED MODELLING PRACTICES}
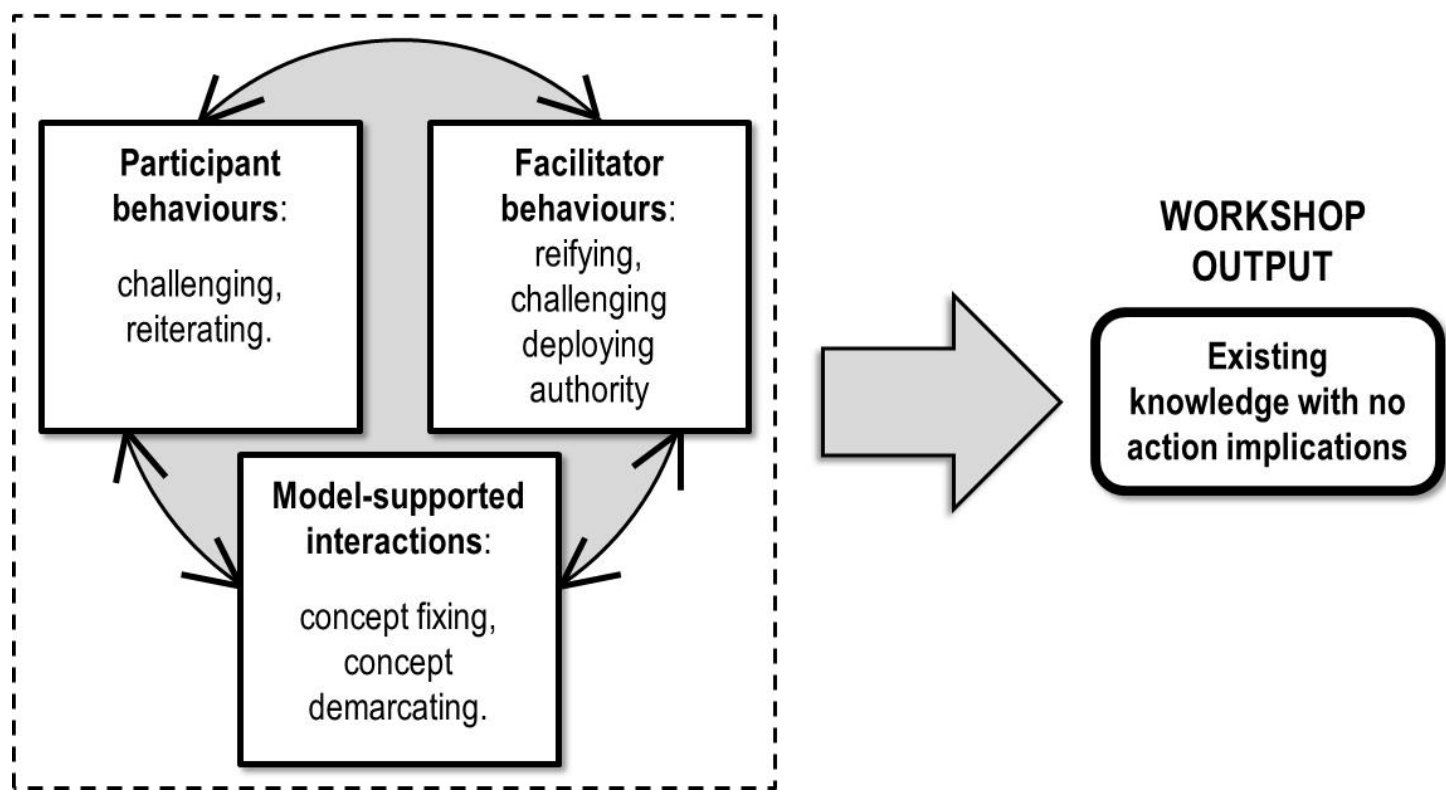